\title{
QTL mapping of a Brazilian bioethanol strain links the cell wall protein-encoding gene GAS1 to low $\mathrm{pH}$ tolerance in S. cerevisiae
}

\author{
Alessandro L. V. Coradini ${ }^{1,2 \dagger}{ }^{\dagger}$, Fellipe da Silveira Bezerra de Mello ${ }^{1 \dagger}$, Monique Furlan ${ }^{1 \dagger}$, Carla Maneira ${ }^{1}$, \\ Marcelo F. Carazzolle1, Gonçalo Amarante Guimaraes Pereira ${ }^{1 *} \mathbb{D}$ and Gleidson Silva Teixeira'
}

\begin{abstract}
Background: Saccharomyces cerevisiae is largely applied in many biotechnological processes, from traditional food and beverage industries to modern biofuel and biochemicals factories. During the fermentation process, yeast cells are usually challenged in different harsh conditions, which often impact productivity. Regarding bioethanol production, cell exposure to acidic environments is related to productivity loss on both first- and second-generation ethanol. In this scenario, indigenous strains traditionally used in fermentation stand out as a source of complex genetic architecture, mainly due to their highly robust background-including low pH tolerance.
\end{abstract}

Results: In this work, we pioneer the use of QTL mapping to uncover the genetic basis that confers to the industrial strain Pedra-2 (PE-2) acidic tolerance during growth at low pH. First, we developed a fluorescence-based highthroughput approach to collect a large number of haploid cells using flow cytometry. Then, we were able to apply a bulk segregant analysis to solve the genetic basis of low $\mathrm{pH}$ resistance in PE-2, which uncovered a region in chromosome $X$ as the major QTL associated with the evaluated phenotype. A reciprocal hemizygosity analysis revealed the allele GAS1, encoding a $\beta-1,3$-glucanosyltransferase, as the casual variant in this region. The GAS1 sequence alignment of distinct $S$. cerevisiae strains pointed out a non-synonymous mutation (A631G) prevalence in wild-type isolates, which is absent in laboratory strains. We further showcase that GAS1 allele swap between PE-2 and a low pH-susceptible strain can improve cell viability on the latter of up to $12 \%$ after a sulfuric acid wash process.

Conclusion: This work revealed GAS1 as one of the main causative genes associated with tolerance to growth at low $\mathrm{pH}$ in PE-2. We also showcase how GAS1 ${ }^{P E-2}$ can improve acid resistance of a susceptible strain, suggesting that these findings can be a powerful foundation for the development of more robust and acid-tolerant strains. Our results collectively show the importance of tailored industrial isolated strains in discovering the genetic architecture of relevant traits and its implications over productivity.

\footnotetext{
*Correspondence: goncalo@unicamp.br

${ }^{\dagger}$ Alessandro L. V. Coradini, Fellipe da Silveira Bezerra de Mello and

Monique Furlan contributed equally to this work

1 Department of Genetics, Evolution, Microbiology, and Immunology,

Institute of Biology, University of Campinas, Rua Monteiro Lobato 255, Campinas 13083-862, Brazil

Full list of author information is available at the end of the article
}

\section{Background}

Saccharomyces cerevisiae strains that are resistant to acidic environments are desirable in many relevant biotechnological processes, from probiotics, food and beverage industries [1-3], to bioethanol production $[4,5]$. Usually, bioethanol is produced from a fermentation process driven by $S$. cerevisiae in which carbon sources from raw feedstock, such as corn, beet, wheat, and sugarcane are employed [6]. The alcohol original author(s) and the source, provide a link to the Creative Commons licence, and indicate if changes were made. The images or other third party material in this article are included in the article's Creative Commons licence, unless indicated otherwise in a credit line to the material. If material is not included in the article's Creative Commons licence and your intended use is not permitted by statutory regulation or exceeds the permitted use, you will need to obtain permission directly from the copyright holder. To view a copy of this licence, visit http://creativecommons.org/licenses/by/4.0/. The Creative Commons Public Domain Dedication waiver (http://creativeco mmons.org/publicdomain/zero/1.0/) applies to the data made available in this article, unless otherwise stated in a credit line to the data. 
production is based on the fermentation of available 6 -carbon sugars from juice and/or starch (first-generation ethanol, E1G), or 5 and 6-carbon sugars present in lignocellulosic material and made available through hydrolysis (second-generation ethanol, E2G) [7]. In the latter, acidic fermentation environments arise as a consequence of the acid treatment of lignocellulosic material, which produces high quantities of acetic acid and other inhibitory by-products, such as 5-hydroxymethylfurfural and furfural [8]. The combination of low $\mathrm{pH}$ and inhibitory by-products perturb the intracellular $\mathrm{pH}$ homeostasis, inducing cell death and consequent loss of productivity $[9,10]$. Therefore, an additional step of $\mathrm{pH}$ neutralization is often required before proceeding to the fermentation process increasing the operational costs [11].

In Brazil, the second-largest bioethanol producer in the world, distilleries commonly use a Melle-Boinot fermentation operation [12], in which high-density cell cultures are applied and the yeast recycled by centrifugation and acid washing to initiate a subsequent fermentation. In short, yeast cells are exposed to an acid treatment with dilute sulfuric acid $\left(\mathrm{H}_{2} \mathrm{SO}_{4}\right)$ for up to $2 \mathrm{~h}$ before being reintroduced into a new vessel for a subsequent cycle of fermentation [13]. This unit operation aims to reduce bacterial contamination and prepare the cells for a new fermentation batch, reducing the need for yeast propagation, thus generating a more productive and less consuming process [14]. However, the severity of the process decreases the viability of the yeast population and consequently reduces productivity [15]. Also, this process may work as a cell bottleneck, limiting the variety of strains that can be used in the process [16].

Given the harsh conditions faced by yeasts in the Brazilian industrial fermentation process, indigenous strains have been praised for their robust background that allows higher ethanol productivity while facing burdening stress factors. In this scenario, S. cerevisiae strain Pedra-2 (PE2) has been described as efficient industrial yeast, able to outperform native yeasts and dominate the fermentation process within a few cycles of fermentation and recycling $[5,17,18]$. The molecular analysis of JAY270 (PE-2 industrial isolate) shed light on its highly heterozygous genome architecture, which harbors structural polymorphisms between homologous chromosomes, especially in peripheral regions. The extreme heterozygosity and plasticity of the PE-2 genome and transcriptome have been hypothesized to contribute to its rapid adaptability to the industrial fermentative environment [19]. In fact, analysis of PE-2 performance during growth at harsh condition demonstrated its superior phenotype when exposed to low $\mathrm{pH}[17,20]$, high temperature and oxidative stress conditions [19].
Responses to acid stress in S. cerevisiae have been thoroughly revised elsewhere [21]. Besides the effects on cell viability [22] and fermentation productivity [23], low $\mathrm{pH}$ can induce oxidative stress [24] and enhance ethanol toxicity [25].

Acid stress can be triggered by the presence of week organic acids (WOA) such as lactic, acetic and formic acid or by inorganic acids mainly sulphuric and hydrochloric. The presence of WOA at external $\mathrm{pH}$ below the weak acid $\mathrm{pK}_{\mathrm{a}}$ value, facilitate the entrance of the undissociated form of the acid ( $\mathrm{RCOOH})$ on the cell by simple diffusion [1]. Once in the neutral cytosol, the chemical dissociation of the weak acid occurs leading to the release of protons $\left(\mathrm{H}^{+}\right)$that strongly decrease the $\mathrm{pH}$ of cell cytoplasm [26]. Thus, the main cell response to this internal acidification involves increasing vacuolar $\mathrm{H}^{+}$-ATPase (V-ATPase) activity [27-34]. Due to the high energetic cost of proton cell extrusion, additional mechanisms to prevent cytosolic acidification are necessary which include alteration of the molecular composition and physical properties of plasma membrane and cell wall [1]. In this scenario, genes related to cell wall remodeling and synthesis of cell wall major polysaccharides-chitin and $\beta$-glucan, and polymers of mannose-are transcriptionally responsive to weak acids [29, 35-39]. Stiffness of the cell wall caused by an increased content of cell wall $\beta$-glucans was recently associated to yeast resistance to acetic acid [40] demonstrating that cell wall remodeling may also play an important role on cell response to acid stress by WOA.

The capacity to maintain and remodel cell wall also appears as the main physiological response to yeast adaptation to inorganic acid exposure. When an inorganic acid is present in the environment, a high concentration of protons is generated. However, distinct from WOA, protons diffuse poorly across the plasma membrane and so the cytoplasm $\mathrm{pH}$ is not drastically reduced [41]. Thus, cell exposure to inorganic acids mainly affects cell wall structure and organization [4, 41, 42]. Previous studies on yeast transcriptional response to low $\mathrm{pH}$ demonstrated that adaptation of yeast involves mechanisms that include induction of cell wall integrity (CWI) genes and general stress response (GSR) pathway mainly due to the action of protein kinase $C(\mathrm{PKC})[36,42-45]$. In particular, genes related to transport, protein anchoring and synthesis of the $\beta$-1,3-glucan chain on yeast cell wall are up-regulated after cell treatment with sulphuric acid [42, 44]. Together these results point to the possibility of the cell wall remodeling, in special changes in its polysaccharides content, as a general response of the cell to acidic environment. Therefore, changes in cell wall structure and content induced by exposure to inorganic acids 
may also lead to an improved resistance to growth in an acidic environment in the presence of either inorganic or organic acids.

In this study, we performed a Quantitative Trait Loci (QTL) mapping approach to unravel the genetic architecture behind the high acid resistance phenotype of the PE-2 strain. We first hypothesized that currently exposure of $\mathrm{PE}-2$ to repetitive cycles of acid treatment with dilute sulfuric acid $\left(\mathrm{H}_{2} \mathrm{SO}_{4}\right)$ in Brazilian bioethanol mills conferred to PE-2 an increased tolerance to low-pH environments. This hypothesis was confirmed by the superior performance of PE-2 over other 41 Saccharomyces sp. strains during growth at low $\mathrm{pH}$ (2.5). Using a high-throughput approach to en masse phenotype of segregants at $\mathrm{pH} 2.1$ followed by a bulk segregant analysis approach (BSA), allows the identification of 2 major loci on chromosome X and XIII. Furthermore, Reciprocal hemizygosity analysis (RHA) revealed the GAS1 allele from PE-2 as the main causal variant associated to loci on Chromosome X. Sequence alignment of different $S$. cerevisiae GAS1 alleles pointed out a persistent non-synonymous mutation within industrial and wild-type isolates, in contrast to laboratory strains. Finally, we showcased that low $\mathrm{pH}$ resistance phenotype can be recovered in susceptible strains with the insertion of PE-2 mutated GAS1. So far, this study presents itself as the first to explore the genetic basis of tolerance to growth at low $\mathrm{pH}$ in S. cerevisiae using a QTL mapping approach. Also, this work may help to better understand the molecular mechanisms underlying relevant industrial traits and, consequently, could foment the development of more robust strains for different applications.

\section{Results}

Screening of parent strains for genetic mapping

The growth performance of the PE-2 isolate, JAY270 (MATa/MAT $\alpha$ ), and other 40 Saccharomyces sp. - including laboratory, industrial and wild-type isolates-was assessed by measuring their relative colony size during growth on rich media at low (2.5) and neutral (6) $\mathrm{pH}$ (Fig. 1A). The JAY270 strain displayed the best growth performance in comparison to the other evaluated strains, presenting only $33 \%$ colony size reduction at low $\mathrm{pH}$. On the other hand, the laboratory strain CEN.PK112 [46] ranked amongst the strains with the lowest performance. JAY270 also outperforms other typically used bioethanol strains (Fig. 1B). Therefore, considering tolerance to growth at low pH, JAY270 and CEN.PK112 were selected as the superior and inferior strain, respectively.

JAY270 segregant haploids were collected using fluorescence-activated cell sorting (FACS) by flow cytometry through a distinct mating-type approach. For this, we constructed vector pMF_002, comprising the reporter gene enhanced green fluorescent protein (EGFP) fused to the MATa-specific STE2 (STErile 2) promoter, and cyan orange fluorescent protein (CyOFP1), to MAT $\alpha$ specific STE3 (STErile 3) promoter (see "Methods" for details). When using only a fluorescein isothiocyanate (FITC) filter, EGFP and CyOFP1 are excited in distinct wavelengths of 515/545 (green) and 655/695 (orange), respectively. Thus, when expressing pMF_002, MATa cells emit green fluorescence and MAT $\alpha$ cells orange

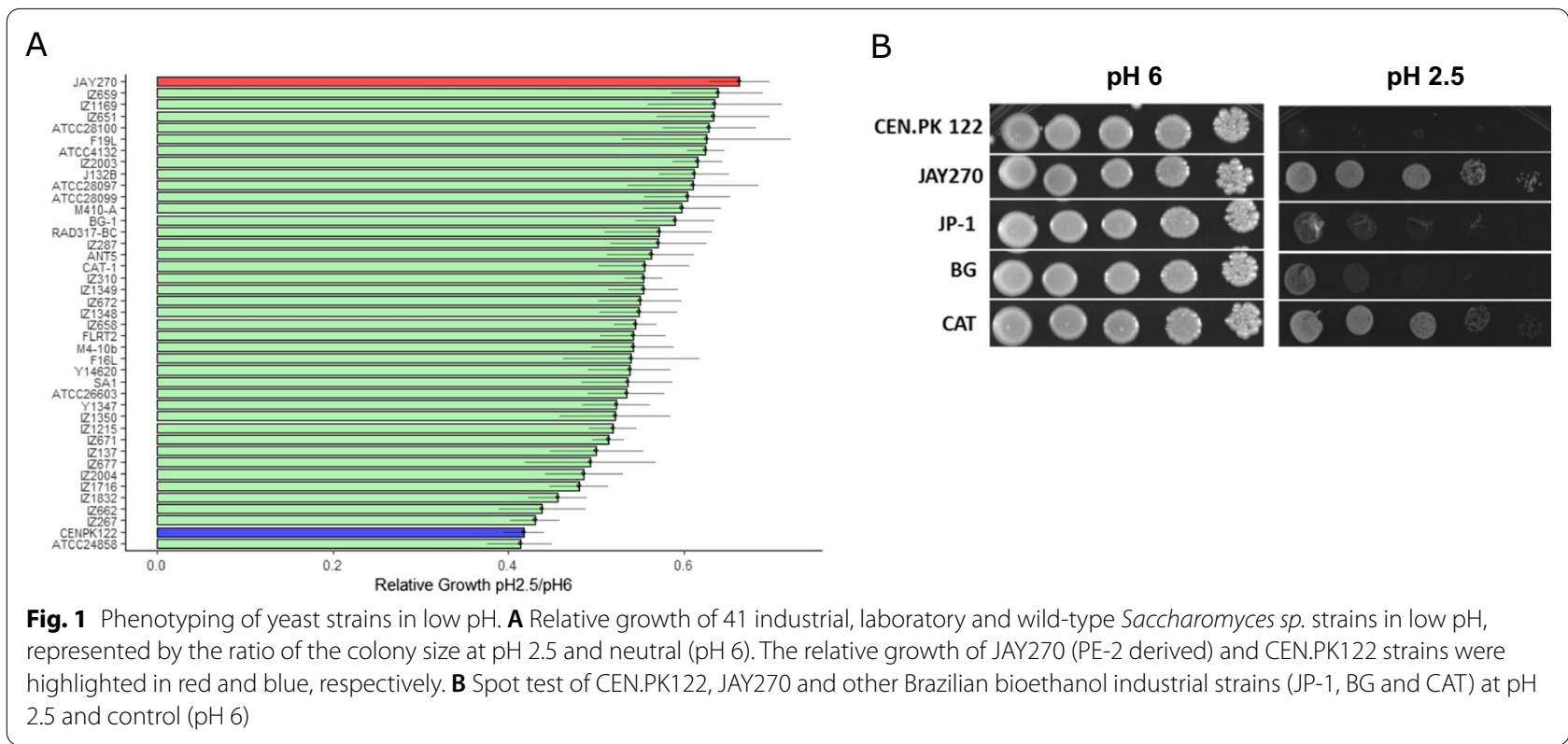


fluorescence, while diploid cells (MATa/MAT $\alpha$ ) and tetrads do not display any fluorescence. This technique allowed the separation and distinct collection of 1084 stable JAY270 haploid cells (Fig. 2). A similar strategy has been previously published by Treusch et al. [47], and here adapted to be suitable for more commonly available excitation wavelengths.

Before proceeding to the phenotyping of the isolated segregants, a minimum inhibitory concentration (MIC) was established for acid tolerance-i.e. the minimum $\mathrm{pH}$ value capable of totally inhibiting the growth of at least one haploid cell. Therefore, the colony size of 48 randomly selected JAY270 segregants was evaluated in decreasing values of $\mathrm{pH}$ (Additional file 1: Fig. S1), and a $\mathrm{pH}$ of 2.1 was selected as the MIC. Next, the panel of 1,084 JAY270 collected haploids was tested for their growth at $\mathrm{pH} 2.1$ to evaluate their phenotypic response.

The normal distribution of the segregants' colony size in the evaluated condition reveals the quantitative characteristic of the low $\mathrm{pH}$ tolerance phenotype in the JAY270 strain (Fig. 3A). In this population, haploid ACY_503 (MATa) presented the largest colony size at $\mathrm{pH} 2.1$, therefore was selected as the superior parental strain. Strain CEN.PK113-1A (MAT $\alpha$ ), CEN.PK122 segregant that presented reduced growth at low $\mathrm{pH}$, was chosen as the inferior parental strain. The crossing between the selected strains resulted in the diploid ACY_503/CEN.PK113-1A. The hybrid diploid and both parental strains were submitted to a colony spot assay to confirm their phenotypes in an acid medium (Fig. 3B). As expected, the resistance and susceptibility of parental haploid strains ACY 503 and CEN.PK 113-1A, respectively, was confirmed. In addition, it is important to notice that the resulting hybrid ACY_503/ CEN.PK113-1A presented low $\mathrm{pH}$ resistance similar to the superior parental ACY_503, indicating that the genetic architecture that underlies the acid tolerance in JAY270 should be dominant.

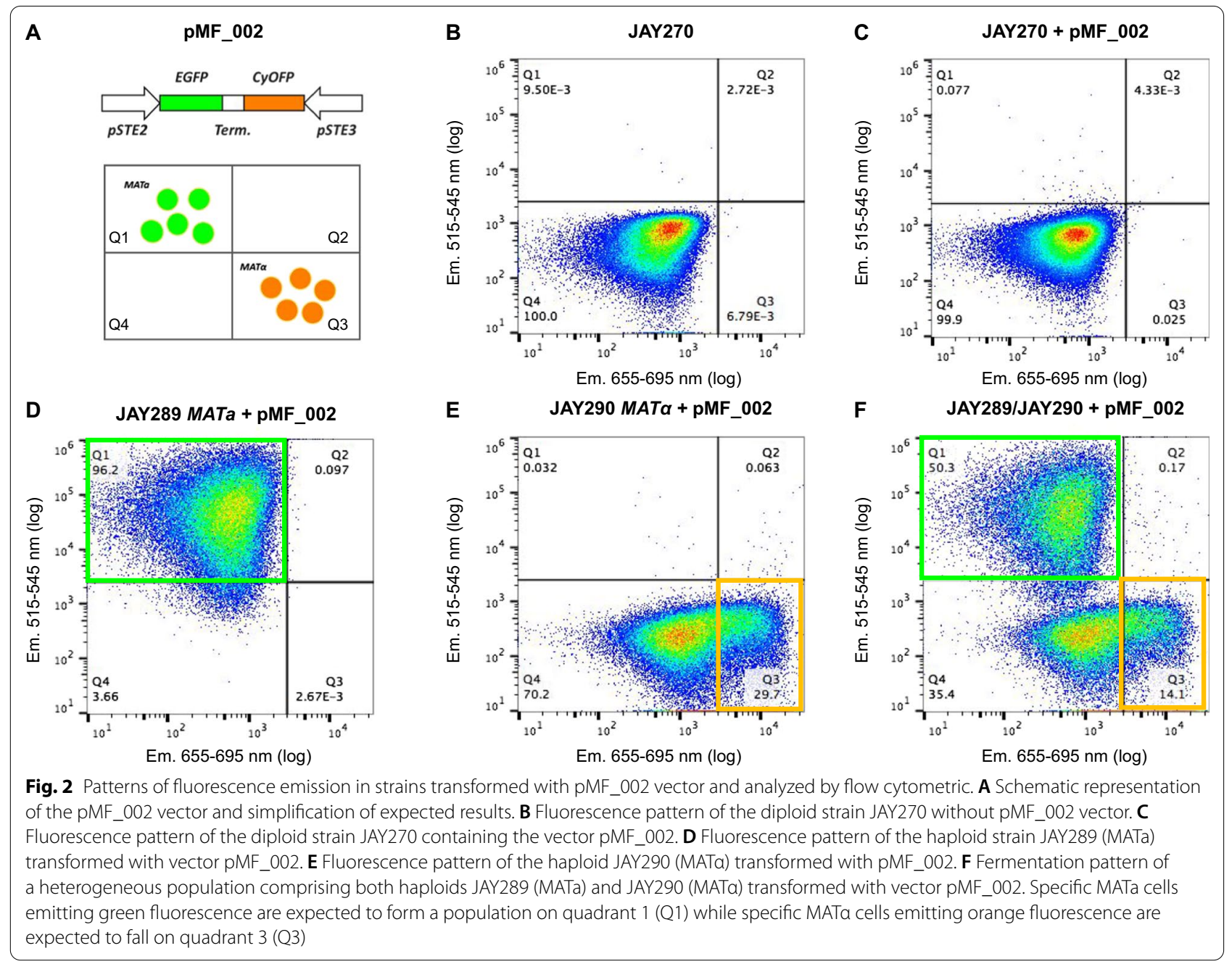




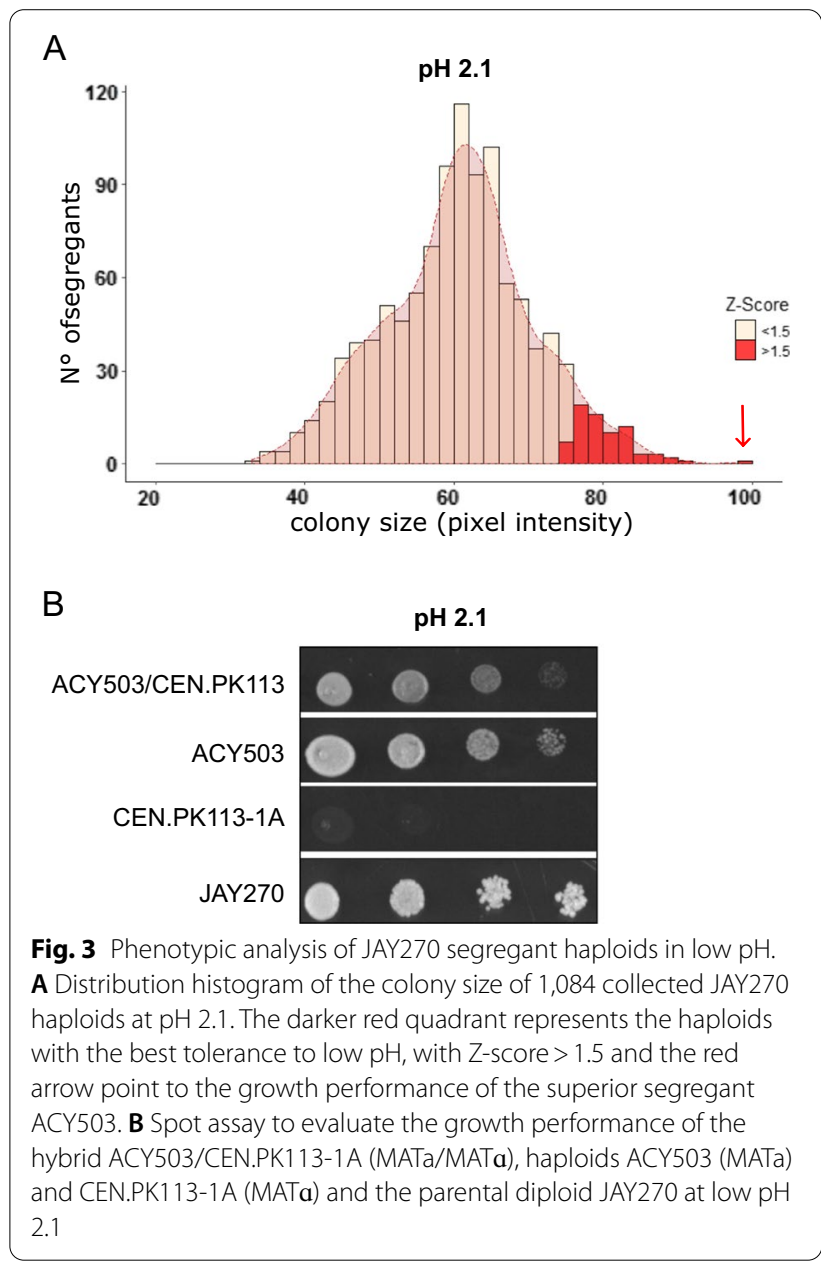

\section{Selection of the two pools of segregants with extreme phenotypes}

The use of the plasmid pMF_002 allowed the application of the bulk segregant analysis (BSA) approach to map potential QTL related to tolerance to growth at low $\mathrm{pH}$ on PE-2. Therefore, ACY_503/CEN.PK113-1A was transformed with the vector pMF_002, sporulated and its segregants were collected using a cell sorter coupled to a flow cytometer. In order to select segregants in the positive extreme of low $\mathrm{pH}$ tolerance phenotypic distribution, the isolated $\mathrm{F}_{2}$ population was collected on YPD plates containing decreasing values of pH: 4, 3, 2.5, and 2.1 (Fig. 4). In this scenario, after $96 \mathrm{~h}$ of incubation, 79 segregants-petite colonies were excluded from this examination-were obtained and labeled as the "high resistance pool" (Additional file 2: Fig. S2A).

One disadvantage of BSA is that it does not allow for the selection of a pool of segregants with inferior phenotype (i.e. haploids susceptible to low $\mathrm{pH}$ ), since en masse selection is provided by increasing the restrictive growth condition. Thus, we randomly selected 500 haploids that were further phenotyped using a colony spot

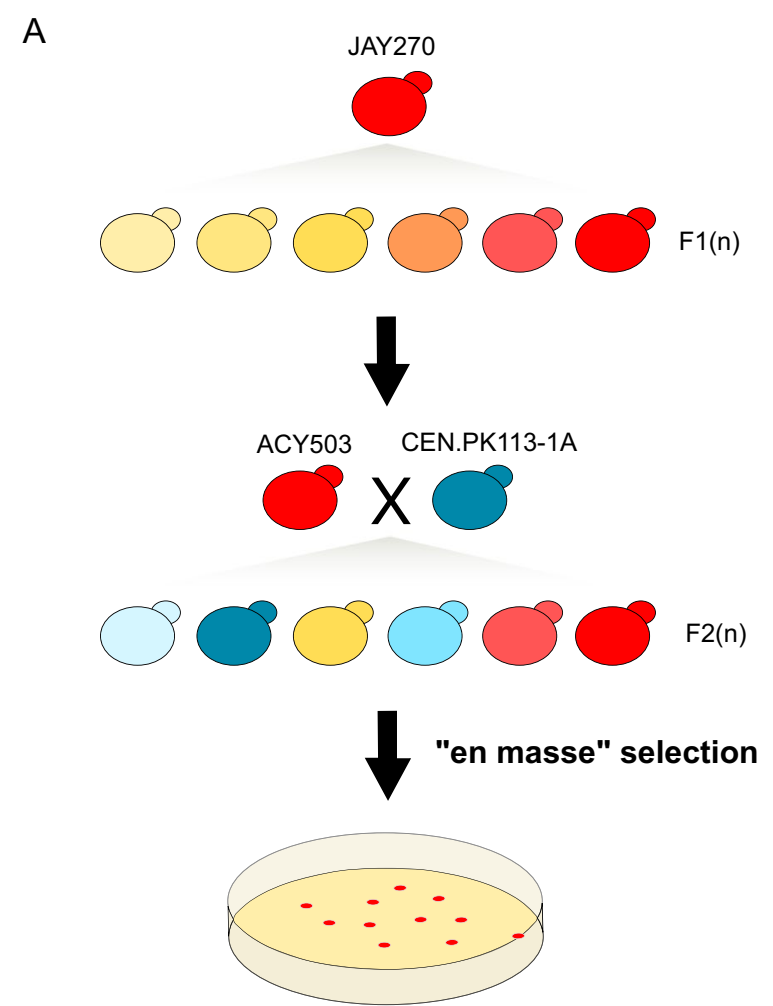

B

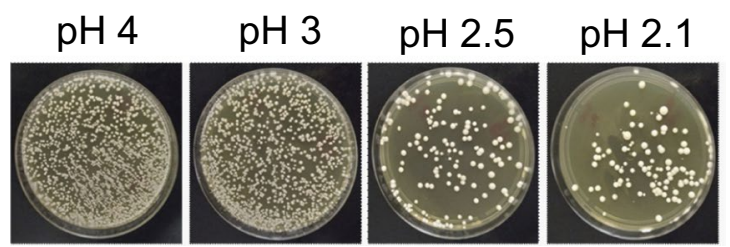

Fig. 4 En masse selection strategy to obtain a pool of low-pH-tolerant segregants from the ACY503/CEN.PK113-1 A cross. A Schematic view of an en masse collection of a pool of ACY503/CEN. PK113-1A acid-tolerant segregants. For the QTL mapping, initially a highly low-pH-resistant JAY270 segregant was selected (ACY503) and further crossed with a haploid of the opposite phenotype. The hybrid transformed with pMF_002 was sporulated and segregants were further collected using a cell sorter coupled with a flow cytometer in growing challenges of $\mathrm{pH}$ resistance. $\mathbf{B}$ Image of YPD plates with decreasing values of $\mathrm{pH}(4,3,2.5$ and 2.1) where 500.000 ACY503/ CEN.PK113-1A segregants were collected in flow cytometry. 79 segregants obtained at $\mathrm{pH} 2.1$ were considered a "high resistance pool" and used for QTL mapping

assay, resulting in 79 segregants with reduced growth at $\mathrm{pH} 2.1$, that were labeled as the "low resistance pool" (Additional file 2: Fig. S2B).

\section{Identification of QTL related to growth tolerance at low $\mathrm{pH}$ of the JAY270 strain}

Genomic DNA of four samples: (i) PE-2-derived superior haploid ACY_503; (ii) laboratory susceptible haploid 
CEN.PK113-1A; (iii) 79 segregants from the high resistance pool; and (iv) 79 segregants from the low resistance pool-were subjected to whole-genome sequencing analysis using the Illumina HiSeq 4000 platform that generated millions of $2 \times 100$ paired-end reads and genome coverages of 213, 170, 267, and 210x, respectively. The reads from the two parental strains and the two pools were first aligned to the CEN.PK113-7D reference genome sequence [48] to identify single nucleotide polymorphisms (SNPs). A total of 47,659 highly credible SNPs between high and low resistance pools were selected for QTL analysis.

The G' values for each SNP were calculated using an 80-kb sliding window, and the p-value graph was plotted to identify the candidate peaks (Fig. 5). Peak regions of - $\log _{10}$ (p-value) above the threshold of 2.3 were defined as candidate QTL regions comprising alleles responsible for the evaluated phenotype. The mapping shows two major peaks: at chromosome X and XIII with $-\log _{10}$ (p-value) of 6.12 and 4.7, respectively. Because chromosome XIII presented the highest value of $-\log _{10}$ ( $\mathrm{p}$-value), therefore representing a region enriched with SNPs more statistically relevant in the high resistance pool, it was selected as the major QTL and used in further analysis.

The mutations present within a region of $50 \mathrm{~kb}$ surrounding the highest peak position on chromosome XIII (897,054 bp) were analyzed and annotated. Initially, all SNPs located in non-coding regions and that confer synonymous mutations were excluded from the list of potential candidates. Further, we used the genome sequence of 14 S. cerevisiae strains, available at Saccharomyces
Genome Database (SGD) [49], to infer the non-synonymous coding SNP frequency in this population (Table 1). Since extreme low $\mathrm{pH}$ tolerance is not a common trait in yeast a low frequency of the candidate SNP was expected. Mutations with frequencies lower than 30\% were, therefore, classified as potential candidates. Finally, we also considered the attributed function for each gene in which the filtered SNP is located to narrow down the number of potential causative alleles.

Using this approach, we were able to identify 4 potential candidate genes on chromosome XIII related to low pH resistance: GAS1, ELP6, GLC8, and FET4. A description of the function of each gene and the non-synonymous uncommon mutations present in ACY_503 can be found in Table 2 .

\section{Validation of the causative genes within chromosome XIII QTL}

The validation of the candidate alleles was performed through RHA. Four pairs of hemizygous ACY_503/CEN. PK113-1A strains were generated, in which each pair retained a single copy of the superior ACY_503 or inferior CEN.PK113-1A parental alleles-GAS1, ELP6, GLC8 or FET4 (Fig. 6A). The hemizygous strains for each candidate allele were tested for growth at $\mathrm{pH} 2.1$ and the phenotypic response assessed through colony spot assays. The results showed that phenotypic variance is present on GAS1 hemizygotes, and that the strain expressing the $G A S 1^{\mathrm{ACY}}{ }^{503}$ allele presented superior growth compared to the one that harbors GAS1 ${ }^{\text {CEN.PK113-1A }}$. On the other hand, the response of the other hemizygous diploid

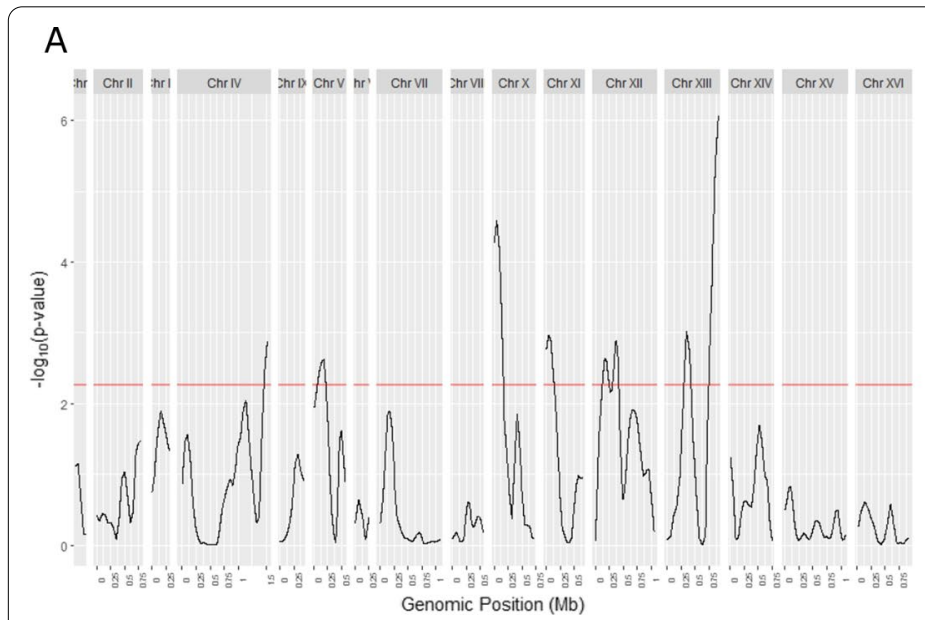

B

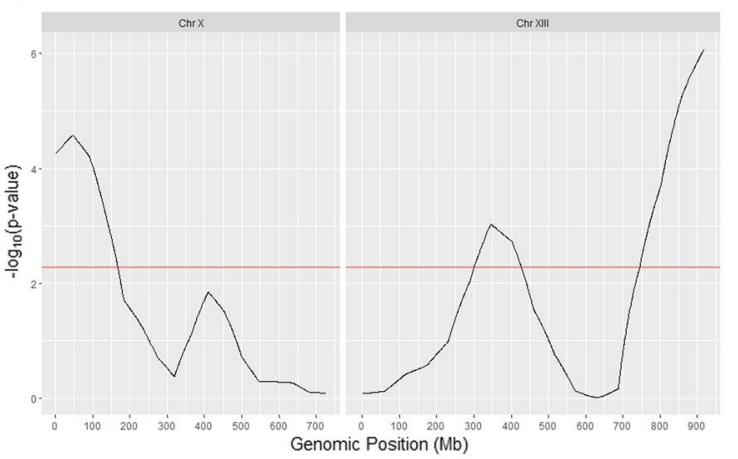

Fig. 5 Mapping of the loci related to low pH tolerance by pooled-segregant whole-genome sequencing analysis. The $X$-axis indicates the chromosome's position; Y-axis indicates the value of - log10(p-value) calculated for windows of $80 \mathrm{~kb}$. The $p$-values are calculated for each SNP and are estimated from the null distribution of G', which assumes no QTL. The threshold value for - log 10(p-value) is indicated by the red line. SNPs that showed $\mathrm{p}$-values above the FDR are considered enriched, deviating from the null distribution hypothesis. A QTL mapping of the whole genome. B QTL mapping of chromosomes X and XIII that presented - $\log _{10}(\mathrm{p}$-value) above the threshold of 2.3 
Table 1 Non-synonymous mutations present in genes within a 50-kb window in chromosome XIII peak (897,054 bp) of low-pH phenotype QTL mapping

\begin{tabular}{|c|c|c|c|c|c|c|c|c|c|c|c|}
\hline & \multicolumn{6}{|l|}{ YME2 } & \multicolumn{3}{|c|}{ UBP15 } & \multirow{2}{*}{$\begin{array}{l}\text { GAS1 } \\
631\end{array}$} & \multirow{2}{*}{$\begin{array}{l}\text { NIP1 } \\
1388\end{array}$} \\
\hline & 255 & 817 & & 1270 & 1408 & 2037 & 916 & 2410 & 2589 & & \\
\hline S288C & A & G & & A & G & G & C & A & A & A & T \\
\hline CEN.PK & G & T & & T & A & T & T & T & T & A & T \\
\hline ACY503 & A & G & & A & G & G & C & A & A & G & A \\
\hline X2180-1A & A & G & & A & G & G & C & A & A & A & T \\
\hline SEY6210 & A & G & & A & G & G & c & A & A & A & T \\
\hline W303 & A & G & & A & G & G & C & A & A & A & A \\
\hline JK9-3d & A & G & & A & G & G & C & A & A & A & T \\
\hline FL100 & A & G & & A & G & G & T & T & T & A & A \\
\hline D273-10B & A & G & & A & G & G & C & A & A & A & T \\
\hline Sigma1278b & A & G & & A & G & G & C & A & A & A & T \\
\hline RM11-1a & G & $\mathrm{T}$ & & T & A & T & C & A & A & G & A \\
\hline SK1 & G & T & & T & A & T & C & T & A & G & A \\
\hline Y55 & G & T & & T & A & T & C & A & A & G & A \\
\hline BY4741 & A & G & & A & G & G & C & A & A & A & T \\
\hline \multirow[t]{3}{*}{ BY4742 } & A & G & & A & G & G & C & A & A & A & T \\
\hline & \multicolumn{3}{|c|}{ YMR310C } & & \multirow{2}{*}{$\begin{array}{l}\text { GLC8 } \\
605\end{array}$} & \multirow{2}{*}{$\begin{array}{l}\text { ELP6 } \\
685\end{array}$} & \multirow{2}{*}{$\begin{array}{l}\text { TGL3 } \\
4\end{array}$} & \multicolumn{2}{|l|}{ DIA1 } & \multicolumn{2}{|l|}{ FET4 } \\
\hline & 1776 & & 442 & & & & & 1495 & 707 & 950 & 1656 \\
\hline S288C & T & & T & & C & c & G & T & T & c & T \\
\hline CEN.PK & T & & T & & C & c & G & T & $\mathrm{T}$ & C & T \\
\hline ACY503 & C & & C & & G & A & A & C & C & T & C \\
\hline X2180-1A & $\mathrm{T}$ & & $\mathrm{T}$ & & C & c & G & $\mathrm{T}$ & $\mathrm{T}$ & c & T \\
\hline SEY6210 & C & & T & & C & C & G & T & T & C & T \\
\hline W303 & T & & c & & G & A & A & C & c & C & T \\
\hline JK9-3d & C & & T & & C & C & G & T & T & C & T \\
\hline FL100 & T & & C & & G & A & A & C & C & C & T \\
\hline D273-10B & T & & T & & c & c & G & T & T & C & T \\
\hline Sigma1278b & T & & T & & C & C & G & T & T & c & T \\
\hline RM11-1a & T & & C & & C & C & G & c & C & C & T \\
\hline SK1 & C & & C & & G & A & A & C & C & c & T \\
\hline Y55 & T & & C & & C & C & A & C & C & c & T \\
\hline BY4741 & T & & $\mathrm{T}$ & & C & C & G & T & T & c & T \\
\hline BY4742 & T & & T & & C & C & G & T & T & C & T \\
\hline
\end{tabular}

strains for the remaining 3 genes not changed on the evaluated condition, compared to the wild-type hybrid.

Next, we sought to identify if swapping GAS1 allele between susceptible and tolerant parental would induce different responses in their acid tolerance phenotype (Fig. 6B). Interchanging the GAS1 allele between both strains significantly improves CEN.PK113-1A tolerance to low $\mathrm{pH}$, while it reduces ACY_503's, corroborating with the results obtained by RHA and strongly suggesting that the GAS1 allele contributes to low $\mathrm{pH}$ tolerance in segregant ACY_503, and consequently in PE-2 strains.
Compared to the CEN.PK113-1A allele, the GAS1 allele of ACY_503 contains one non-synonymous point mutation, within its coding sequence (position $887,003 \mathrm{bp}$ on chromosome XIII). This mutation accounts for a nucleotide exchange at position 631 from adenine to guanine and results in a threonine to alanine substitution. The GAS1 allele from ACY_503 also harbors a synonymous mutation at position 1314 bp (i.e. a cytosine replacing thymine).

Next, we compared GAS1 sequence from ACY_503 and other 1053 Saccharomyces cerevisiae strains containing 
Table 2 Possible causative alleles related to low-pH-resistance phenotype at chromosome XIII with uncommon non-synonymous coding mutations

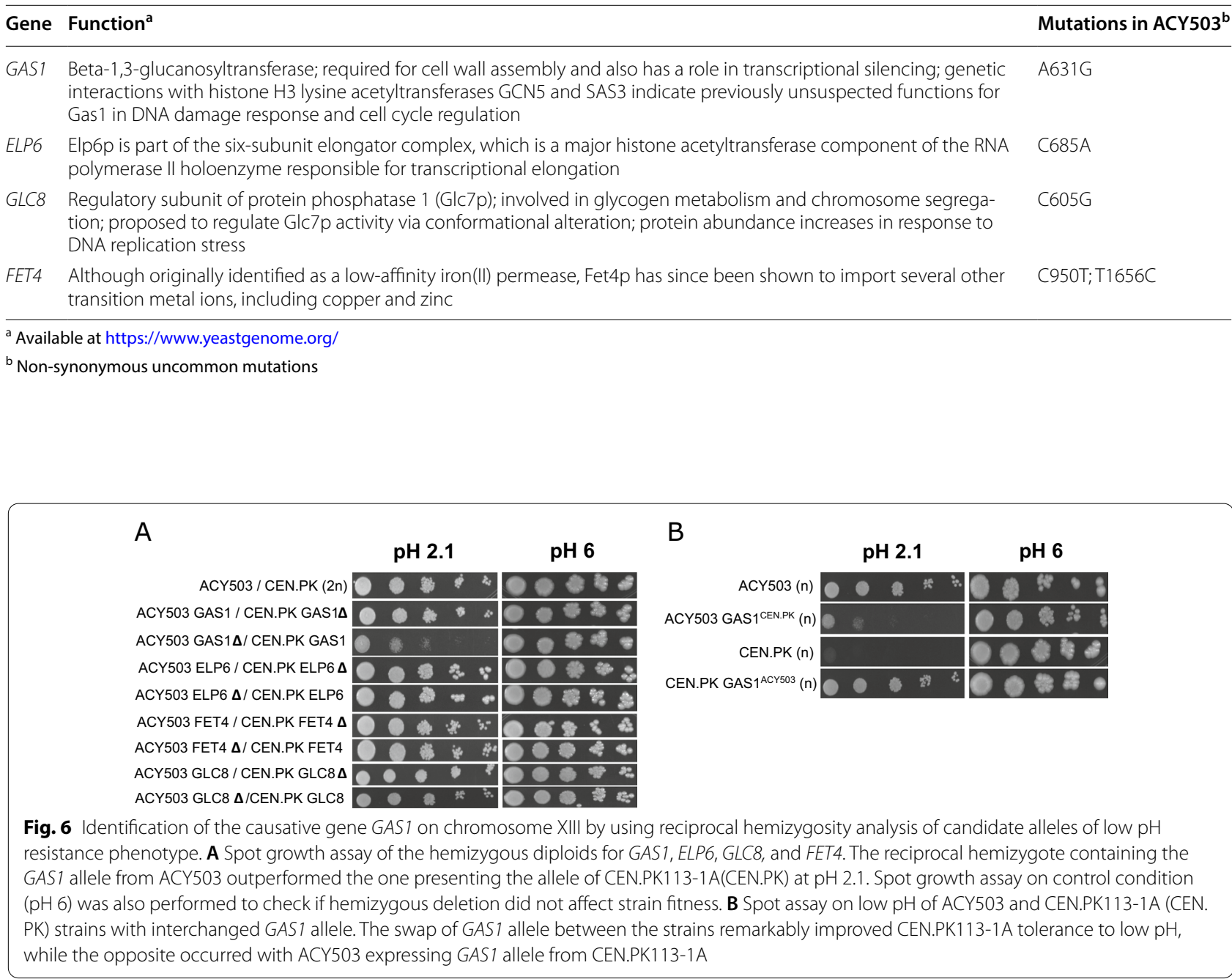

Table 3 Evaluation of GAS1 SNPs frequency in 1053 distinct Saccharomyces cerevisiae strains

\begin{tabular}{|c|c|c|c|c|c|}
\hline \multirow[t]{2}{*}{$\begin{array}{l}\text { SNP } \\
\text { location } \\
\text { in GAS1 }\end{array}$} & \multirow[t]{2}{*}{ Nucleotide } & \multicolumn{2}{|c|}{$\begin{array}{l}\text { Total Saccharomyces } \\
\text { cerevisiae } \\
\text { population }\end{array}$} & \multicolumn{2}{|c|}{$\begin{array}{l}\text { Brazilian bioethanol } \\
\text { strain population }\end{array}$} \\
\hline & & $\begin{array}{l}\text { Number } \\
\text { of } \\
\text { strains }\end{array}$ & $\begin{array}{l}\text { SNP } \\
\text { frequency } \\
\text { (\%) }\end{array}$ & $\begin{array}{l}\text { Number } \\
\text { of strains }\end{array}$ & $\begin{array}{l}\text { SNP } \\
\text { frequency } \\
(\%)\end{array}$ \\
\hline \multirow[t]{3}{*}{631} & $\begin{array}{l}\text { A (refer- } \\
\text { ence) }\end{array}$ & 32 & 3.0 & 0 & 0 \\
\hline & G & 1019 & 96.8 & 39 & 100 \\
\hline & $\mathrm{R}(\mathrm{A}$ or $\mathrm{G})$ & 2 & 0.2 & 0 & 0 \\
\hline \multirow[t]{3}{*}{1314} & $\mathrm{~T}$ (reference) & 54 & 92.0 & 7 & 17.9 \\
\hline & C & 969 & 5.1 & 30 & 76.9 \\
\hline & $Y(C$ or $T)$ & 30 & 2.8 & 2 & 5.1 \\
\hline
\end{tabular}

laboratorial and wild isolate whose genome sequencing is available at Saccharomyces genome database (SGD) [49] and Peter et al. [50]. The frequency of non-synonymous mutation found on ACY_503 is high (96.8\%) in the total S. cerevisiae analyzed population (Table 3 ). Interestingly, this mutation seems common throughout the majority of wild-type isolated strains, including all the Brazilian bioethanol isolates, while it is not found on laboratory ones (Additional file 3: Table S1). The same analysis was carried out for the synonymous mutation at nucleotide 1314 and distinct from the non-synonymous one it presents a low frequency (5.1\%) on total analyzed population. However, this frequency increases to $76.9 \%$ when the analyzed population includes only isolates from Brazilian Bioethanol process (Table 3). 
Analysis of the CEN.PK113-1A GAS1 ${ }^{\mathrm{ACY}-503}$ mutant tolerance to acid-wash treatment with $\mathrm{H}_{2} \mathrm{SO}_{4}$ solution.

As previously stated, the $\mathrm{E} 1 \mathrm{G}$ production process in Brazilian mills has the peculiarity of using the Melle-Boinot operation, characterized by fed-batch fermentation cycles with high-density cell recycle. Yeast cells are recycled up to 3 times per day and, between each recycling step, face an acid-wash treatment with sulfuric acid $(\mathrm{pH} \sim 1.5)$ that aims to reduce bacterial contamination and flocculation $[16,51]$. Thus, after linking the GAS1 allele to PE-2 tolerance to growth at low $\mathrm{pH}$, we sought to explore if it is possible to increase tolerance to an acid-wash treatment in a naturally susceptible strain after allele swap (i.e. by constructing a strain expressing GAS1 $1^{\mathrm{ACY} 503}$ allele).

For this purpose, wild-type CEN.PK113-1A strain and its mutant CEN.PK113-1A GAS1 $1^{\mathrm{ACY} \text { 503 }}$ were submitted to an acid treatment in which cells were exposed to a diluted $\mathrm{H}_{2} \mathrm{SO}_{4}$ solution with $\mathrm{pH} 1.5$ for up to $3 \mathrm{~h}$. Viability was assessed every hour, revealing that the CEN.PK113$1 \mathrm{~A}$ strain containing the mutated GAS1 allele presents superior cell viability when compared to the wild type. After $3 \mathrm{~h}$ of exposure to $\mathrm{H}_{2} \mathrm{SO}_{4}$ solution, CEN.PK113$1 \mathrm{~A}$ cell containing GAS1 allele maintaining $12 \%$ more viable cells when compared to wild type CEN.PK113-1A (Fig. 7).

\section{Discussion}

QTL mapping approaches have been extensively used to unravel the genetic basis of complex traits in a wide range of organisms [52]. In the yeast S. cerevisiae, QTL mapping approaches have facilitated the association between genetic variants and industrially relevant traits [53]. In this scenario, wild-type isolated strains present a higher degree of genetic and natural selection-driven diversity

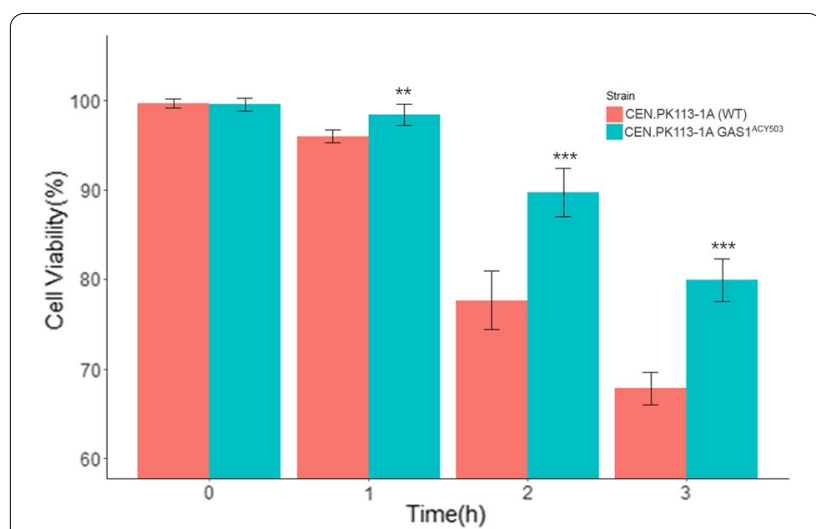

Fig. 7 Cell viability after acid-wash assay. Cell viability of CEN. PK113-1A and its mutant containing the GAS1 allele from the tolerant strain ACY503 was assessed each hour during $3 \mathrm{~h}$ of treatment with $\mathrm{H}_{2} \mathrm{SO}_{4}$ solution compared with domesticated laboratory ones, which facilitate their use to resolve the genetic basis of sodesired relevant traits. In this study, a bioethanol industrial strain-PE-2, isolated from Brazilian mills-was used to unravel potential genetic variants associated with tolerance to growth at low $\mathrm{pH}$ in S. cerevisiae.

An initial evaluation of growth performance of JAY270 (PE-2 derivate) and other $40 \mathrm{~S}$. cerevisiae strains cultivated at a low $\mathrm{pH}$ condition confirmed the superior phenotype of PE-2, especially when compared to the laboratory strain CEN.PK122. In fact, PE-2 persistence on the ethanol production process in Brazilian mills has already been associated with its resistance to the acidwash cell recycle step typically performed on Brazilian E1G production process $[5,20]$. On the other hand, common laboratory strains such as CEN.PK122 are typically cultivated under standard conditions that include slightly acidic $\mathrm{pH}$ and consequently do not undergo natural selection for this specific condition. Our initial result corroborates with the idea that the harsh conditions faced by yeast strains during bioethanol production produce tailored strains that can easily outcompete non-adapted ones. Thus, industrial isolated strains from the Brazilian bioethanol process, such as PE-2, SA-1, CAT-1, BG-1 can be a good source of genetic variability to explore the genetic basis of industrial relevant traits.

In order to investigate the genetic architecture of PE-2 acid tolerance, we first developed a high-throughput fluorescence-based approach to isolate a large number of yeast segregants. In comparison to other BSA approaches, such as X-QTL [54], our method allows the rapid generation of large mapping populations without extensive strain engineering. Despite the similarity to the fluorescence-based approach described by Treusch et al. [47], our method has the advantage of decreasing the number of wavelength gates necessary for segregant isolation. It makes use of the eGFP and CyOFP1 fluorescent proteins, which are excited at wavelengths of 515/545 (green) and 655/695 (orange), respectively, via a single FITC filter. This is the first report of the use of CyOFP1 in a fluorescent-based approach for yeast cell separation.

The developed fluorescence-based approach was successfully applied to isolate a large pool of segregants for BSA-based QTL mapping. BSA is an efficient approach for detection of major QTLs associated with complex traits in yeast [55-63]. This approach relies on phenotyping a progeny from a cross and genotyping two subsets of these offspring presenting opposite phenotypes [64]. The developed fluorescence-based approach was successfully applied to isolate a large pool of segregants (500.000) from a cross between the ACY_503 (PE-2 derivative) and CEN.PK113-1A strains. The segregants were collected in crescent challenging conditions of low $\mathrm{pH}$, which allowed 
the selection of a pool of 79 superior and inferior haploids-representing less than $0.01 \%$ of the total analyzed population.

By analyzing differential SNPs presence in both pools ( $\triangle$ SNP-index), we were able to identify a major QTL located at the end of chromosome XIII. Although the QTL region encompasses a genomic window of approximately $150 \mathrm{~kb}$ containing several genes, we focused our analysis on the $50 \mathrm{~kb}$ window surrounding the detected QTL peak. We also applied a protein function analysis as well as non-synonymous mutation information in these genes, narrowing down the number of potential candidates to only 4. Through generation of engineered reciprocal hemizygotes, we were able to identify GAS1 as the causative allele on the major QTL at chromosome XIII. Furthermore, by interchanging the GAS1 alleles between ACY 503 and CEN.PK113-1A, we remarkably increased CEN.PK113-1A tolerance to low pH condition. Both results indicate GAS1 as the causal variant on QTL at chromosome XIII responsible for low $\mathrm{pH}$ tolerance on PE-2 strain.

GAS1 encodes a cell wall-bound 1,3-beta-glucanosyltransferase involved in the formation and maintenance of 1,3-beta-glucan, which is the major polysaccharide of the cell wall (see review on [65]). The Gas1p is a GPIanchored glycoprotein of $125-130 \mathrm{kDa}$ localized at the plasma membrane and is a member of the GH72 family of $\beta$-1,3-glucanosyltransferases that also include the Candida albicans $\mathrm{pH}$-responsive proteins-CaPhr1p and CaPhr2p [66]. The enzyme is characterized by an $\mathrm{N}$-terminal catalytic domain of about 310 residues (D23P332), known as the $\beta-(1,3)$-glucan transferase domain (GluTD), a cysteine-rich region containing a motif of eight cysteines (C370-C462) and a serine-rich region in which 28 serines are clustered in a region between residues S485 and S525 [67].

A comparison between ACY_503 and CEN.PK113-1A alleles showed the presence of two distinct mutations at nucleotides positions 631 and 1314, non-synonymous and synonymous, respectively. Thus, the non-synonymous mutation at A211 amino acid residue is located at $\mathrm{N}$-terminal catalytic domain and more precisely on $\alpha$-helices domain between the two activity glutamates residues E161 and E262 necessary for GAS1 activity as b-(1,3)-glucanase and b-(1,3)-glucanosyltransferase [68].

A more comprehensive analysis of the presence of both SNPs in other S. cerevisiae strains revealed that the non-synonymous mutation is common on wild strains isolated from distinct sources-e.g. wineries, bioethanol industries and oak trees. On the other hand, this mutation is absent in laboratory domesticated strains such as S288C, CEN.PK and W303. Yeasts are known to be organisms with the capacity to survive and ferment in a more acidic environment- $\mathrm{pH} 4-5$ [41, 69]. Acidification of the extracellular environment can be a consequence of natural processes occurring during fermentation, presence of competing microorganisms producing organic acids or as a consequence of human interference during a biotechnological process [4]. However, acidic environments are rare in controlled laboratory conditions, where yeast growth is typically carried out in standard conditions that include neutral and controlled $\mathrm{pH}$. The lack of selective pressure in laboratory growth conditions may have contributed to the loss of beneficial genetic variants associated with low $\mathrm{pH}$ resistance on laboratory strains.

Regarding the synonymous mutation at nucleotide 1314, it appears enriched in the Brazilian bioethanol strain population when compared to the total analyzed population (Table 3). This result may point to a positive selection of this mutation on the strains used in Brazilian bioethanol process. Although synonymous mutations are not expected to cause phenotypic changes, there is emerging evidence that it may affect cell fitness by altering translational efficiency, mRNA stability and also perturbing co-translational protein folding mechanisms [70-72].

The Gas1p role on yeast low $\mathrm{pH}$ resistance may be related to activation of cell wall integrity (CWI) pathway. The CWI pathway is responsible for maintenance and function of the yeast cell wall and its mechanism is controlled by the regulatory cascade led by protein kinase [73]. In summary, the stress sensor Mid2 mediates a response to acidic conditions that leads to activation of the $\mathrm{R} \operatorname{lm} 1$ transcription factor through phosphorylation of MAP kinase Slt2p/Mpk1p [74, 75]. Gas1D mutant strains show hypersensitivity to low $\mathrm{pH}$ and present higher levels of dually phosphorylated Slt2, which may help explain the connection between Gas1p and CWI pathway. Some studies have also demonstrated the existence of a synthetic interaction between Gas1p, Slt2p and Rlm1 [76]. Collectively these results point that maintenance of cell wall structure is an important response to low $\mathrm{pH}$ stress. Corroborating with this idea, transcriptomic analysis of yeast cells growing under low $\mathrm{pH}$ showed that GAS1 and other genes related to cell wall biogenesis appear up-regulated as a response to the damages caused by strong inorganic acids such as sulphuric acid [42], a stress response that may be triggered by CWI pathway activation.

Recently, Ribeiro et al. [40] demonstrated that Gas1p also play a role in yeast cell wall response to stress caused by organic acid such as acetic acid. The presence of $60 \mathrm{mM}$ of acetic acid ( $\mathrm{pH} 4.0)$ in the medium up-regulates the transcription of $\beta$-1,3-glucanosyltransferase encoded by gene GAS1 that leads to an increased content of cell wall $\beta$-glucans. This correlation between the 
increased levels of GAS1's transcripts and the content of glucan in the cell wall suggests that at least partially, the cell wall remodeling under acetic acid presence is due to the action of $\beta$-1,3-glucanosyltransferase encoded by GAS1. This remodeling is essential for preventing acetate (dissociated form of acetic acid due to the low $\mathrm{pH}$ ) entry through passive diffusion into the cell.

The GAS1 was also identified as responsible for low $\mathrm{pH}$ resistance of the multiple-stress-tolerant yeast Issatchenkia orientalis (Pichia kudriavzevii) [68]. Matsushika et al. have screened on S. cerevisiae a genomic DNA library of $I$. orientalis identifying loGAS1 as the allele responsible for low $\mathrm{pH}$ resistance and also demonstrating that expression of loGAS1 in S. cerevisiae (S288C) improved its ethanol fermentation ability at $\mathrm{pH}=2$. In a complementary study, the same group demonstrated that $S$. cerevisiae GAS1 (ScGAS1) expression is pH-dependent and increases in low $\mathrm{pH}$ conditions [77]. Also, overexpression of ScGAS1 improved growth and ethanol production under acid stress conditions, although the stress tolerance was inferior to that of the IoGAS1-overexpressing strain. The DNA sequences of both genes-loGAS1 and ScGAS1, possess approximately $60 \%$ of similarity [68]. Interestingly, by analyzing and comparing the amino acids profile from loGas1p with the Gas1p produced by the ACY_503 and CEN.PK113-1A alleles, we found that the non-synonymous mutation present in the ACY_503 allele result in the same amino acid (alanine) as at that position in the loGAS1 gene.

Finally, to build evidence that GAS1 $1^{\mathrm{ACY}_{5} 503}$ may also play a role to PE-2 tolerance to acid-wash treatment of the cell recycle process on Brazilian bioethanol mills, we analyzed the cell survival rate of the susceptible strain CEN.PK113-1A and its mutant CEN.PK113-1A GAS1 ${ }^{\text {ACY }} 503$ when submitted to a $\mathrm{H}_{2} \mathrm{SO}_{4}$ solution. The result showed that the strain harboring mutant GAS1 allele preserves up to $12 \%$ more viable cells after 2 and $3 \mathrm{~h}$ of acid treatment. This result might be indicative of PE-2 strain tolerance to the acid-wash treatment and its prevalence on fermentation vessels, as described by Basso et al. [16]. Furthermore, this result also opens the possibility of using genetic engineering to develop more robust strains for ethanol production (E1G and E2G) and also other biotechnological processes where cells experienced loss of cell viability or productivity due to the acidic environment.

\section{Conclusion}

In this study, we explored the industrial isolated strain $\mathrm{PE}-2$ resistance to growth at low $\mathrm{pH}$. By using a highthroughput approach, we were able to isolate and collect thousands of segregants and apply a BSA to map the QTL related to this phenotype. Following, a RHA approach allowed us to uncover the allele GAS1 as one of the causal variant related to low $\mathrm{pH}$ tolerance by $\mathrm{PE}-2$. Further, we used reverse genetic engineering to improve tolerance to acidic $\mathrm{pH}$ of the strain CEN.PK113-1A, demonstrating that GAS1 $1^{\mathrm{ACY}-503}$ is able to confer this phenotype. This study is, up to date, the first study that used the QTL approach to solve the genetic basis of tolerance to low $\mathrm{pH}$ in yeast. The knowledge provided here may help develop more robust strains for ethanol production and also other yeast-based industrial processes.

\section{Methods}

\section{Strains and plasmids}

A total of 41 Saccharomyces sp. strains (Additional file 4: Table S2) were used for the screening of low-pH tolerance phenotype in yeast. Diploid industrial S. cerevisiae PE-2 [19] was used as the acid-resistant reference strain,

Table 4 Main Saccharomyces cerevisiae strains used in this work

\begin{tabular}{|c|c|c|}
\hline Strain & Description & Source \\
\hline PE-2 & Brazilian ethanol mill indigenous diploid strain & Basso et al. [5] \\
\hline CEN.PK113-1A (CEN.PK) & MATa (prototrophic) & Euroscarf \\
\hline ACY503 & MATa, haploid segregant from PE-2 & This study \\
\hline ACY503/CEN.PK113-1A & Hybrid diploid strain from the crossing of ACY503 and CEN.PK113-1A & This study \\
\hline ACY503 gas 1/CEN.PK gas $1 \triangle$ & ACY503 crossed with CEN.PK113-1A gas1 1 & This study \\
\hline ACY503 $\triangle$ gas 1/CEN.PK gas1 & ACY503 gas $1 \triangle$ crossed with CEN.PK113-1A & This study \\
\hline ACY503 elp6/CEN.PK elp6 & ACY503 crossed with CEN.PK113-1A elp6 & This study \\
\hline ACY503 $\triangle$ elp6/CEN.PK elp6 & ACY503 elp6 $\Delta$ crossed with CEN.PK113-1A & This study \\
\hline ACY503 fet4/CEN.PK fet4 $\triangle$ & ACY503 crossed with CEN.PK113-1A fet4 $\triangle$ & This study \\
\hline ACY503 fet4 $\triangle$ /CEN.PK fet41 & ACY503 fet4 $\triangle$ crossed with CEN.PK113-1A & This study \\
\hline ACY503 glc8/CEN.PK glc8 & ACY503 crossed with CEN.PK113-1A glc8D & This study \\
\hline ACY503 glc8 $4 / C E N . P K$ glc8 & ACY503 glc8D crossed with CEN.PK113-1A & This study \\
\hline
\end{tabular}


and ACY_503 (PE-2, MATa) its superior tolerant haploid. Non-tolerant laboratory MAT $\alpha$ CEN.PK113-1A was used for the crossing with ACY_503 to generate hybrid ACY_503/CEN.PK113-1A, whose $F_{2}$ progeny was used in low $\mathrm{pH}$ assays. The main $S$. cerevisiae strains used in this work are presented in Table 4. Escherichia coli DH5 $\alpha$ was used in cloning procedures for plasmids used in this study. Plasmid pMF002 (pMATa-EGFP-tMATa; tMAT $\alpha$ CyOFP-pMAT $\alpha$; KanMX) was used for high-throughput separation and collection of segregants using flow cytometry.

\section{Growth media}

YPD medium (10 g/L yeast extract; $20 \mathrm{~g} / \mathrm{L}$ peptone; $20 \mathrm{~g} / \mathrm{L}$ D-glucose), solidified with $15 \mathrm{~g} / \mathrm{L}$ agar when required, was used for yeast propagation. G418 $(200 \mu \mathrm{g} /$ $\mathrm{mL})$, hygromycin $\mathrm{B}(300 \mathrm{mg} / \mathrm{ml})$ were added to the medium for the selection of strains with a KanMX or hphMX6 resistant marker, respectively. For stress-screening procedures, $1 \mathrm{M} \mathrm{H}_{2} \mathrm{SO}_{4}$ was used to adjust YPD pH before autoclaving. For sporulation procedures, $1 \%(\mathrm{~m} / \mathrm{v})$ KAc supplemented with a complete drop-out solution $(460 \mathrm{mg} / \mathrm{mL})$ was used. Cultivation occurred at $30^{\circ} \mathrm{C}$ and $250 \mathrm{rpm}$ unless otherwise noticed. Bacteria were grown in Luria-Bertani (LB) broth $(10 \mathrm{~g} / \mathrm{L}$ tryptone, $10 \mathrm{~g} / \mathrm{L}$ $\mathrm{NaCl}, 5 \mathrm{~g} / \mathrm{L}$ yeast extract) supplemented with $100 \mu \mathrm{g} / \mathrm{mL}$ ampicillin at $37^{\circ} \mathrm{C}$.

\section{General molecular biology}

Yeast transformation was carried out with the PEG/LiAc method [78]. Transformation of the DH10 $\beta$ E. coli cells was done by the standard heat shock method. Bacterial plasmid purification was performed with a standard miniprep protocol [79]. Genomic DNA was extracted with (LiOAc)-SDS/EtOH fast protocol [80] for PCR purposes. All PCR reactions were performed with Phusion ${ }^{\circledR}$ High Fidelity DNA Polymerase following the manufacturer's instructions (NEB-New England Biolabs).

\section{$F_{1}$ mating and sporulation}

ACY503 and CEN.PK113-1A strains were matted by scratching them over an YPD plate. Ploidy of isolated colonies was checked by PCR and the diploid strain ACY503/CEN.PK113-1A was obtained. The diploid strain was further transformed with plasmid pMF_002. Sporulation was induced in conical glass tubes containing $2 \mathrm{~mL}$ of $1 \% \mathrm{KAc}$ medium and $100 \mu \mathrm{L}$ of a saturated culture of the diploid ACY503/CEN.PK113-1A expressing pMF_002. Tetrad formation was checked by microscope and when $80 \%$ of the culture has formed by tetrads, the cells were harvested and submitted to an asci lysis assay.

\section{$F_{2}$ spore disruption and segregant collection}

ACY_503/CEN.PK113-1A spore disruption was performed as follows: $250 \mu \mathrm{L}$ of pelleted sporulated culture were resuspended in $100 \mu \mathrm{L}$ of micromanipulation buffer (1 M sorbitol) with $1 \mu \mathrm{L}$ of $\beta$-mercaptoethanol previously added. After, $16 \mu \mathrm{L}$ of cells was added to a new Eppendorf tube containing $20 \mu \mathrm{L}$ of Lyticase $(0.5 \mathrm{mg} / \mathrm{mL})$. The tube was vortexed and incubated at $30{ }^{\circ} \mathrm{C}$ during $3 \mathrm{~h}$ with shaking at $900 \mathrm{rpm}$. Digestion was checked by light microscopy and stopped with the addition of $100 \mu \mathrm{L}$ of distilled water. The cell suspension was then vortexed for $2 \mathrm{~min}$ and centrifuged for $1 \mathrm{~min}$, the supernatant was removed and the tube was sonicated twice for $1 \mathrm{~min}$ at level $2(20 \%)$ and then diluted to $\mathrm{OD}_{660}=0.4$ in $1 \mathrm{X}$ PBS.

BD FACSAria flow cytometer III (BD-Bioscience) coupled with a cell sorter was used to sort 500,000 green $(515 / 545)$ or orange $(655 / 695)$ fluorescent cells each, using a FITC filter $(488 \mathrm{~nm})$. Sorted cells were added to $10 \mathrm{~mL}$ YPD containing $100 \mu \mathrm{g} / \mathrm{mL}$ ampicillin in glass tubes and grown for $6 \mathrm{~h}$. Cultures were spun down for $5 \mathrm{~min}$ at 3,000 rpm and after supernatant removal cells were resuspended in $950 \mu \mathrm{l}$ water. $200 \mu \mathrm{L}$ of cell suspension were then plated in low-pH media ranging from 1.9 to 4 . Plates were grown for $120 \mathrm{~h}$ and ploidy of the hypothetical segregants was assessed by multiplex PCR. In summary, genomic DNA from each colony was extracted using the protocol described by Looke [80]. Further, the extracted DNA was used as template for a multiplex PCR reaction using two distinct pairs of primers that anneal specifically to the MATa or MAT $\boldsymbol{\alpha}$ locus. The presence of a single band at 500 or $600 \mathrm{bp}$ indicates that the analyzed colony poses a MATa or MATa locus, respectively. The presence of both bands in a single reaction indicates the presence of both loci in the same analyzed colony indicating that cells are diploids.

\section{Colony spot assay for Saccharomyces sp. screening at low-pH conditions}

Yeast phenotyping was performed as described by Takeshi et al. [81]. Initially, strains were grown overnight in 96-well plates containing $200 \mu \mathrm{L}$ YPD. Plates were then vigorously shaken to disperse cells and a replicator block tool was used to inoculate strains on solid plates containing different low-pH conditions. Replicates were performed in three randomized positions to minimize technical errors. Growth of each strain was assessed by colony size captured by plate image using Gel Doc ${ }^{\mathrm{TM}}$ $\mathrm{XR}+$ Gel Documentation System (BIO-RAD, USA). The dimensions of all the images were set at $13.4 \times 10 \mathrm{~cm}$ (W $\times \mathrm{L}$ ) and imaged under white Epi illumination with $0.5 \mathrm{~s}$ exposure time. Every colony pixel intensity was measured using Image). The total pixel intensity within a circle (spot 
radius $=50$ pixels) surrounding each colony in the image was measured using the Plate Analysis JRU v1 plugin for ImageJ (http://research.stowers.org/imagejplugins/index. html). The average pixel intensity was determined by dividing the total pixel intensity by the area of the circle examined (7845 pixels2). Finally, relative growth is calculated as the ratio between the average pixel intensity of the strain colony growing on low-pH media and control (YPD) condition.

\section{Preparation of DNA samples}

Parental strains ACY_503 and CEN.PK113-1A, as well as 79 superior and inferior segregants pools for low $\mathrm{pH}$ assay were individually inoculated in $2 \mathrm{~mL}$ YPD medium and grown to the stationary phase at $30{ }^{\circ} \mathrm{C}$. The genomic DNA was pooled extracted using the methods described by Pais et al. [82]. For each pool and condition, $\mathrm{OD}_{660}$ of each culture was individually assessed and the cells were mixed in equivalent concentrations to form a heterogeneous pool containing approximately the same cell concentration representative for each strain. DNA was extracted according to the procedures described by Ausubel et al. [83] and DNA concentration and quality were estimated with a Nanodrop 3000 UV-Vis spectrophotometer (Wilmington, DE, USA). The two pools and parental DNA were prepared for Illumina sequencing.

\section{Pooled-segregant whole-genome sequence analysis and QTL mapping}

At least $5 \mu \mathrm{g}$ of gDNA from the superior and inferior low-pH resistance phenotype pools and parental strains were provided to Central Laboratory of High Performance Technologies in Life Sciences (LaCTAD) from the University of Campinas (UNICAMP) for whole-genome sequencing using the Illumina HiSeq 2500 platform. $2 \times 100$ paired-end reads were generated and aligned to the genome sequence of the CEN.PK113-7D reference strain [48]. Bowtie2 program version 2.3.5.1 [84] was used to align the paired-end reads of each sample against the reference genome. Alignment files were converted to BAM files using samtools software version 1.3.1 [85]. In addition, potential PCR duplicates were removed using picard version 2.23.9 command "MarkDuplicates" [86], in which if multiple read pairs have identical external coordinates, only the pair with the highest mapping quality is retained. SNP calling was performed using GATK (v4.0.12.0) base quality score recalibration, indel realignment and SNP and INDEL discovery and genotyping across the two samples (hard and low resistance pool) using standard high filtering parameters [66]. For each pool the ploidy level was configured to 79 (number of haploid individuals in each pool).

The statistical analysis of QTLs was performed as proposed by Magwene et al. [87] using QTLseqR package version 0.7.0. A modified $G$ statistic is calculated for each SNP based on the observed and expected allele depths and the value is smoothed using a NadarayaWatson, or tricube smoothing kernel. This smoothing method weights neighboring SNPs' G statistic by their relative distance from the focal SNP such that closer SNPs receive higher weights. The analysis was performed with an R package called QTLseqr [88]. In short, the command runGprimeAnalysis() was used to calculate the G statistic for each SNP. It then counts the number of SNPs within the set window bandwidth and estimates the tricube-smoothed G' and $\Delta$ (SNPindex) values of each SNP within that window. For both analyses a sliding window of $80 \mathrm{~kb}$ size was used to calculate G' of each SNP. The results were presented as - $\log (\mathrm{p}$-value) since $\mathrm{p}$-values can be estimated from the null distribution of G, which assumes no QTL and provides a more direct statistical interpretation of QTL mapping.

\section{Reciprocal hemizygosity analysis (RHA)}

Hemizygous diploid strains were constructed by deleting the evaluated gene in one of the parental strains and crossing the haploid mutant with the opposite mating type parental strain. For example, to create the hemizygous diploid strain for GAS1 allele, a knockout of the gene was performed on ACY_503 parental strain and further crossed to wild-type CEN.PK113-1A, creating the heterozygous diploid ACY_503/CEN.PK113-1A GAS1 $\Delta /$ GAS1. The opposite strategy was made to obtain the heterozygous diploid strain ACY_503/CEN.PK113-1A GAS1/GAS1 $\Delta$. Genetic modifications were checked via PCR.

\section{Acid wash treatment assay}

The CEN.PK113-1A and CEN.PK113-1A GAS1 ${ }^{\mathrm{ACY} \_503}$ strains were cultivated overnight until reaching stationary phase (12-16 h). Further, cells were washed $3 \times$ with water to remove media and diluted on a water solution with $\mathrm{pH} 1.5$ corrected by addition of $\mathrm{H}_{2} \mathrm{SO}_{4} 3 \mathrm{M}$. Cells were kept on this solution under low agitation $(50 \mathrm{rpm})$ and aliquots were taken every hour to assess cell viability. Cell viability was measured by staining an aliquot of cells $(10 \mu \mathrm{L})$ with the same volume of Trypan Blue $0,4 \%$. The solution was properly diluted and cells counted using a 
Neubauer chamber. The dye exclusion test is based upon the concept that viable cells do not take up impermeable dyes (like Trypan Blue), but dead cells are permeable and take up the dye.

\section{Supplementary Information}

The online version contains supplementary material available at https://doi. org/10.1186/s13068-021-02079-6.

Additional file 1. Phenotypic distribution of 48 JAY270 segregants growing on solid YPD containing decreasing concentrations of $\mathrm{pH}$ to define the Minimum Inhibitory Concentration. A. Boxplot graph containing the colony size values of $48 \mathrm{JAY} 270$ segregants growing on solid YPD at different pH values $(4 ; 3.5 ; 3 ; 2.5 ; 2.1)$. B. Images of each low pH plate containing the 48 segregants evaluated on this minimum inhibitory concentration assay. The images were captured 96 hours after plating.

Additional file 2. Spotting assay for growing at low pH (2.1) of ACY503/ CEN.PK113-1A segregants belonging to the "high resistant pool" (A) and "low resistant pool" (B). Each lane represents a different isolated colony and the columns the dilution factor applied to the initial cultures before spotting.

Additional file 3. GAS1 mutation profile of 1053 distinct Saccharomyces cerevisiae strains.

Additional file 4. List of 41 Saccharomyces sp. strains evaluated during growth at low pH (2.5).

\section{Acknowledgements}

We would like to thank Professor Dr. Alessandro dos Santos Farias from University of Campinas (Brazil) and Dr. Felipe Franco da Rocha of the Bioinformatics section of the Life Sciences Core Facility (LaCTAD), part of the University of Campinas (Brazil), for their contributions to flow cytometry analysis. Also, we want to thank Professor Dr. Luis Humberto Gomes, in memoriam, from University of São Paulo (Brazil) for providing us with the Saccharomyces sp strains library. Finally, we thank the Core Facility for Scientific Research-University of Sao Paulo (CEFAP-USP/FLUIR) for the use of equipment FACSAria III for flow cytometry analysis and cell sorting.

\section{Authors' contributions}

ALVC conducted all experiments and wrote the manuscript. FSBM provided important discussion and support throughout this study and helped on manuscript writing process. ALVC and MFC analyzed genomic data. CM contributed to the genetic engineering of the strains. MF developed the plasmid used for segregant collection in flow cytometry. GAGP and GST conceived and supervised the project. All authors read and approved the final manuscript.

\section{Funding}

This study was financed by the Center for Computational Engineering and Science (FAPESP/CEPID 2013/08293-7); the National Agency of Petroleum, Natural Gas and Biofuels (ANP), Brazil, associated with the investment of resources from the P, D \& I Clauses; the Sinochem Petróleo Brasil Ltda; and the Fundação de Amparo à Pesquisa do Estado de São Paulo (FAPESP, São Paulo, Brazil) through a scholarship to ALVC (Grant Number 2014/26719-4), MF (Grant Number 2016/12852-0), FSBM (Grant Number 2015/06677-8), CM (Grant Number 2018/03403-2) and GST (BIOEN Grant Number 2016/02506-7).

\section{Declarations}

\section{Ethics approval and consent to participate} Not applicable.

\section{Consent for publication}

Not applicable.

\section{Availability of data and materials}

The complete dataset of DNA-seq reads have been deposited in SRA under accession number PRJNA755995.

\section{Competing interests}

The authors declare that they have no competing interests.

\section{Author details}

'Department of Genetics, Evolution, Microbiology, and Immunology, Institute of Biology, University of Campinas, Rua Monteiro Lobato 255, Campinas 13083-862, Brazil. ${ }^{2}$ Molecular and Computational Biology Section, Department of Biological Sciences, University of Southern California, Los Angeles, CA 90089-2910, USA.

Received: 18 August 2021 Accepted: 17 November 2021

Published online: 16 December 2021

\section{References}

1. Mira NP, Teixeira MC, Sá-Correia I. Adaptive response and tolerance to weak acids in Saccharomyces cerevisiae: a genome-wide view. OMICS. Mary Ann Liebert, Inc.; 2010;14:525-40.

2. Piper $\mathrm{P}, \mathrm{Calderon} \mathrm{CO}$, Hatzixanthis $\mathrm{K}$, Mollapour M. Weak acid adaptation: the stress response that confers yeasts with resistance to organic acid food preservatives. Microbiol Microbiol Soc. 2001;147:2635-42.

3. Russell AD. Mechanisms of bacterial resistance to non-antibiotics: food additives and food and pharmaceutical preservatives. J Appl Bacteriol. 1991;71:191-201.

4. De MHF, Bonini BM, Thevelein J, Simões DA, Morais MA. Physiological and molecular analysis of the stress response of Saccharomyces cerevisiae imposed by strong inorganic acid with implication to industrial fermentations. J Appl Microbiol. 2010;109:116-27.

5. Basso LC, Basso TO, Rocha SN. Ethanol Production in Brazil: the industrial process and its impact on yeast fermentation. Biofuel Prod Dev Prospect. IntechOpen; 2011

6. Goldemberg J. The Brazilian biofuels industry. Biotechnol Biofuels. 2008;1:6.

7. dos Santos LV, de Barros Grassi MC, Gallardo JCM, Pirolla RAS, Calderón LL, de Carvalho-Netto OV, et al. Second-Generation Ethanol: The Need is Becoming a Reality. Ind. Biotechnol. Mary Ann Liebert, Inc. 140 Huguenot Street, 3rd Floor New Rochelle, NY 10801 USA ; 2016;12:40-57.

8. Klinke HB, Thomsen AB, Ahring BK. Inhibition of ethanol-producing yeast and bacteria by degradation products produced during pre-treatment of biomass. Appl Microbiol Biotechnol. 2004;66:10-26.

9. Jansen MLA, Bracher JM, Papapetridis I, Verhoeven MD, de Bruijn H, de Waal PP, et al. Saccharomyces cerevisiae strains for second-generation ethanol production: from academic exploration to industrial implementation. FEMS Yeast Res. 2017:17:44.

10. Narayanan V, Schelin J, Gorwa-Grauslund M, van Niel EW, Carlquist M. Increased lignocellulosic inhibitor tolerance of Saccharomyces cerevisiae cell populations in early stationary phase. Biotechnol Biofuels. 2017:10:1-15.

11. Yang $Q$, Yang $Y$, Tang $Y$, Wang $X$, Chen $Y$, Shen $W$, et al. Development and characterization of acidic-pH-tolerant mutants of Zymomonas mobilis through adaptation and next-generation sequencing-based genome resequencing and RNA-Seq. Biotechnol Biofuels. 2020;13:1-17.

12. Zanin GM, Santana CC, Bon EPS, Giordano RCL, De Moraes FF, Andrietta SR, et al. Brazilian bioethanol program. Appl Biochem Biotechnol Humana Press. 2000;84-86:1147-62.

13. da Silva-Filho EA, Santos dos SKB, Resende do AM, de Morais JOF, de Morais MA, Simões DA. Yeast population dynamics of industrial fuelethanol fermentation process assessed by PCR-fingerprinting. Antonie Van Leeuwenhoek. 2005;88:13-23.

14. Laluce C, Schenberg ACG, Gallardo JCM, Coradello LFC, Pombeiro-Sponchiado SR. Advances and developments in strategies to improve strains of saccharomyces cerevisiae and processes to obtain the lignocellulosic ethanol-a review. Appl Biochem Biotechnol. 2012;166:1908-26.

15. Della-Bianca BE, Basso TO, Stambuk BU, Basso LC, Gombert AK. What do we know about the yeast strains from the Brazilian fuel ethanol industry? Appl Microbiol Biotechnol. 2013;97:979-91. 
16. Basso LC, de Amorim HV, de Oliveira AJ, Lopes ML. Yeast selection for fuel ethanol production in Brazil. FEMS Yeast Res. 2008;8:1155-63.

17. Della-Bianca BE, Gombert AK. Stress tolerance and growth physiology of yeast strains from the Brazilian fuel ethanol industry. Antonie Van Leeuwenhoek. 2013;104:1083-95.

18. Carvalho-Netto OV, Carazzolle MF, Rodrigues A, Bragança WO, Costa GGL, Argueso JL, et al. A simple and effective set of PCR-based molecular markers for the monitoring of the Saccharomyces cerevisiae cell population during bioethanol fermentation. J Biotechnol Elsevier. 2013;168:701-9.

19. Argueso JL, Carazzolle MF, Mieczkowski PA, Duarte FM, Netto OVC, Missawa SK, et al. Genome structure of a Saccharomyces cerevisiae strain widely used in bioethanol production. Genome Res. 2009;19:2258-70.

20. Della-Bianca BE, de Hulster E, Pronk JT, van Maris AJA, Gombert AK. Physiology of the fuel ethanol strain Saccharomyces cerevisiae PE-2 at low $\mathrm{pH}$ indicates a context-dependent performance relevant for industrial applications. FEMS Yeast Res. 2014;14:1196-205.

21. Guan N, Liu L. Microbial response to acid stress: mechanisms and applications. Appl Microbiol Biotechnol. 2019;104:51-65.

22. Brosnan MP, Donnelly D, James TC, Bond U. The stress response is repressed during fermentation in brewery strains of yeast. J Appl Microbiol. 2000;88:746-55.

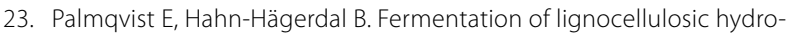
lysates. II: inhibitors and mechanisms of inhibition. Bioresour Technol. 2000;74:25-33

24. Guo Z, Olsson L. Physiological responses to acid stress by Saccharomyces cerevisiae when applying high initial cell density. FEMS Yeast Res. 2016;16:72.

25. Lam FH, Ghaderi A, Fink GR, Stephanopoulos G. Engineering alcohol tolerance in yeast. Sci Am Assoc Adv Sci. 2014;346:71-5.

26. Fernández-Niño M, Pulido S, Stefanoska D, Pérez C, González-Ramos $D$, van Maris AJA, et al. Identification of novel genes involved in acetic acid tolerance of Saccharomyces cerevisiae using pooled-segregant RNA sequencing. FEMS Yeast Res. 2018;18.

27. Fernandes AR, Mira NP, Vargas RC, Canelhas I, Sá-Correia I. Saccharomyces cerevisiae adaptation to weak acids involves the transcription factor Haa $1 \mathrm{p}$ and Haa1p-regulated genes. Biochem Biophys Res Commun. 2005;337:95-103.

28. Kawahata M, Masaki K, Fujii T, lefuji H. Yeast genes involved in response to lactic acid and acetic acid: acidic conditions caused by the organic acids in Saccharomyces cerevisiae cultures induce expression of intracellular metal metabolism genes regulated by Aft1p. FEMS Yeast Res FEMS Yeast Res. 2006;6:924-36.

29. Mira NP, LourenÃßo AB, Fernandes AR, Becker JD, SÃi-Correia I. The RIM101 pathway has a role in Saccharomyces cerevisiae adaptive response and resistance to propionic acid and other weak acids. FEMS Yeast Res. 2009;9:202-16

30. Mollapour M, Fong D, Balakrishnan K, Harris N, Thompson S, Schüller C, et al. Screening the yeast deletant mutant collection for hypersensitivity and hyper-resistance to sorbate, a weak organic acid food preservative. Yeast. 2004:21:927-46.

31. Schüller C, Mamnun YM, Mollapour M, Krapf G, Schuster M, Bauer BE, et al. Global phenotypic analysis and transcriptional profiling defines the weak acid stress response regulon in Saccharomyces cerevisiae. Mol Biol Cell Am Soc Cell Biol. 2004;15:706-20.

32. Desmoucelles C, Pinson B, Saint-Marc C, Daignan-Fornier B. Screening the yeast "Disruptome" for mutants affecting resistance to the immunosuppressive drug, mycophenolic acid. J Biol Chem J Biol Chem. 2002;277:27036-44.

33. Fernandes AR, Durão PJ, Santos PM, Sá-Correia I. Activation and significance of vacuolar H+-ATPase in Saccharomyces cerevisiae adaptation and resistance to the herbicide 2,4-dichlorophenoxyacetic acid. Biochem Biophys Res Commun. 2003;312:1317-24.

34. Meijnen J-P, Randazzo P, Foulquié-Moreno MR, van den Brink J, Vandecruys $P$, Stojiljkovic $M$, et al. Polygenic analysis and targeted improvement of the complex trait of high acetic acid tolerance in the yeast Saccharomyces cerevisiae. Biotechnol Biofuels. 2016;9:1-18.

35. Abbott DA, Suir E, van Maris AJA, Pronk JT. Physiological and transcriptional responses to high concentrations of lactic acid in anaerobic chemostat cultures of Saccharomyces cerevisiae. Appl Environ Microbiol Am Soc Microbiol (ASM). 2008;74:5759-68.

36. Kapteyn JC, Ter Riet B, Vink E, Blad S, De Nobel H, Van Den Ende H, et al. Low external pH induces HOG1-dependent changes in the organization of the Saccharomyces cerevisiae cell wall. Mol Microbiol Mol Microbiol. 2001;39:469-80.

37. Mira NP, Palma M, Guerreiro JF, Sá-Correia I. Genome-wide identification of Saccharomyces cerevisiae genes required for tolerance to acetic acid. Microb Cell Factories. 2010;9:1-13.

38. Mira NP, Becker JD, Sá-Correia I. Genomic expression program involving the Haa1p-regulon in Saccharomyces cerevisiae response to acetic acid. https://home.liebertpub.com/omi. Mary Ann Liebert, Inc. 140 Huguenot Street, 3rd Floor New Rochelle, NY 10801 USA; 2010;14:587-601.

39. Dong Y, Hu J, Fan L, Chen Q. RNA-Seq-based transcriptomic and metabolomic analysis reveal stress responses and programmed cell death induced by acetic acid in Saccharomyces cerevisiae. Sci Rep. 2017;7:1-16.

40. Ribeiro RA, Vitorino MV, Godinho CP, Bourbon-Melo N, Robalo TT, Fernandes $F$, et al. Yeast adaptive response to acetic acid stress involves structural alterations and increased stiffness of the cell wall. Sci Rep. 2021;11:1-9.

41. Chen AKL, Gelling C, Rogers PL, Dawes IW, Rosche B. Response of Saccharomyces cerevisiae to stress-free acidification. J Microbiol J Microbiol. 2009;47:1-8.

42. de Lucena RM, Elsztein C, de Barros Pita W, de Souza RB, de Sá Leitão Paiva Júnior S, de Morais Junior MA. Transcriptomic response of Saccharomyces cerevisiae for its adaptation to sulphuric acid-induced stress. Antonie Van Leeuwenhoek. 2015:108:1147-60.

43. de Lucena RM, Elsztein C, Simões DA, de Morais MA. Participation of CWI, HOG and Calcineurin pathways in the tolerance of Saccharomyces cerevisiae to low pH by inorganic acid. J Appl Microbiol. 2012;113:629-40.

44. Lucena RM, Dolz-Edo L, Brul S, de Morais MA, Smits G. Extreme low cytosolic pH is a signal for cell survival in acid stressed yeast. Genes. 2020;11:656.

45. Claret S, Gatti X, Doignon F, Thoraval D, Crouzet M. The Rgd1p Rho GTPase-activating protein and the Mid2p cell wall sensor are required at low pH for protein kinase $\mathrm{C}$ pathway activation and cell survival in Saccharomyces cerevisiae. Eukaryot Cell Am Soc Microbiol. 2005;4:1375-86.

46. van Dijken J, Bauer J, Brambilla L, Duboc P, Francois J, Gancedo C, et al. An interlaboratory comparison of physiological and genetic properties of four Saccharomyces cerevisiae strains. Enzyme Microbial Technol. 2000;26:706-14.

47. Treusch S, Albert FW, Bloom JS, Kotenko IE, Kruglyak L. Genetic mapping of MAPK-mediated complex traits across S. cerevisiae. PLoS Genet. 2015;11:e1004913.

48. Nijkamp JF, van den Broek M, Datema E, de Kok S, Bosman L, Luttik MA, et al. De novo sequencing, assembly and analysis of the genome of the laboratory strain Saccharomyces cerevisiae CEN.PK113-7D, a model for modern industrial biotechnology. Microb Cell Fact. 2012;11:36.

49. Cherry JM, Adler C, Ball C, Chervitz SA, Dwight SS, Hester ET, et al. SGD: Saccharomyces genome database. Nucleic Acids Res. 1998;26:73-9.

50. Peter J, De Chiara M, Friedrich A, Yue J-X, Pflieger D, Bergström A, et al. Genome evolution across 1,011 Saccharomyces cerevisiae isolates. Nat. 2018 5567701. Nature. 2018:556:339-44.

51. Prado CD, Mandrujano GPL, Souza JP, Sgobbi FB, Novaes HR, da Silva JPMO, et al. Physiological characterization of a new thermotolerant yeast strain isolated during Brazilian ethanol production, and its application in high-temperature fermentation. Biotechnol Biofuels. 2020;13:1-15.

52. Wilkening S, Lin G, Fritsch ES, Tekkedil MM, Anders S, Kuehn R, et al. An evaluation of high-throughput approaches to QTL mapping in Saccharomyces cerevisiae. Genetics. 2014;196:853-65.

53. Liti G, Louis EJ. Advances in quantitative trait analysis in yeast. PLoS Genet. 2012;8:e1002912.

54. Ehrenreich IM, Torabi N, Jia Y, Kent J, Martis S, Shapiro JA, et al. Dissection of genetically complex traits with extremely large pools of yeast segregants. Nature. 2010;464:1039-42.

55. Meijnen J-P, Randazzo P, Foulquié-Moreno MR, van den Brink J, Vandecruys $P$, Stojiljkovic M, et al. Polygenic analysis and targeted improvement of the complex trait of high acetic acid tolerance in the yeast Saccharomyces cerevisiae. Biotechnol Biofuels. 2016;9:5. 
56. De Carvalho BT, Holt S, Souffriau B, Brandão RL, Foulquié-Moreno MR, Theveleina JM. Identification of novel alleles conferring superior production of rose flavor phenylethyl acetate using polygenic analysis in yeast. MBio. 2017;8.

57. Wang Z, Qi Q, Lin Y, Guo Y, Liu Y, Wang Q. QTL analysis reveals genomic variants linked to high-temperature fermentation performance in the industrial yeast. Biotechnol Biofuels. 2019;12:1-18.

58. Swinnen S, Schaerlaekens K, Pais T, Claesen J, Hubmann G, Yang Y, et al. Identification of novel causative genes determining the complex trait of high ethanol tolerance in yeast using pooled-segregant whole-genome sequence analysis. Genome Res. 2012;22:975-84.

59. Cubillos FA, Brice C, Molinet J, Tisné S, Abarca V, Tapia SM, et al. Identification of nitrogen consumption genetic variants in yeast through QTL mapping and bulk segregant RNA-Seq analyses. G3 Genes Genomes Genetics. 2017;7:1693-705.

60. Brice C, Sanchez I, Bigey F, Legras JL, Blondin B. A genetic approach of wine yeast fermentation capacity in nitrogen-starvation reveals the key role of nitrogen signaling. BMC Genomics. 2014;15.

61. Eder M, Sanchez I, Brice C, Camarasa C, Legras J-L, Dequin S. QTL mapping of volatile compound production in Saccharomyces cerevisiae during alcoholic fermentation. BMC Genomics. 2018;19:166.

62. Hubmann G, Mathé L, Foulquié-Moreno MR, Duitama J, Nevoigt E, Thevelein JM. Identification of multiple interacting alleles conferring low glycerol and high ethanol yield in Saccharomyces cerevisiae ethanolic fermentation. Biotechnol Biofuels. 2013;6.

63. Feng L, Jia H, Qin Y, Song Y, Tao S, Liu Y. Rapid identification of major QTLS associated with near-freezing temperature tolerance in Saccharomyces cerevisiae. Front Microbiol Front. 2018;9:2110.

64. Michelmore RW, Paran I, Kesseli RV. Identification of markers linked to disease-resistance genes by bulked segregant analysis: a rapid method to detect markers in specific genomic regions by using segregating populations. Proc Natl Acad Sci. 1991;88:9828-32.

65. Klis FM, Mol P, Hellingwerf K, Brul S. Dynamics of cell wall structure in Saccharomyces cerevisiae. FEMS Microbiol Rev. 2002;26:239-56.

66. Ragni E, Fontaine T, Gissi C, Latgè JP, Popolo L. The Gas family of proteins of Saccharomyces cerevisiae: characterization and evolutionary analysis. Yeast. 2007;24:297-308.

67. Carotti C, Ragni E, Palomares O, Fontaine T, Tedeschi G, Rodríguez R, et al. Characterization of recombinant forms of the yeast Gas 1 protein and identification of residues essential for glucanosyltransferase activity and folding. Eur J Biochem. 2004;271:3635-45.

68. Matsushika A, Negi K, Suzuki T, Goshima T, Hoshino T. Identification and characterization of a novel Issatchenkia orientalis GPI-anchored protein, loGas1, required for resistance to low pH and salt stress. In: Yang S, editor. PLoS One. 2016;11:e0161888.

69. Ariño J. Integrative Responses to High pH Stress in S. cerevisiae. https:// home.liebertpub.com/omi. Mary Ann Liebert, Inc. 140 Huguenot Street, 3rd Floor New Rochelle, NY 10801 USA ; 2010;14:517-23.

70. Hunt RC, Simhadri VL, landoli M, Sauna ZE, Kimchi-Sarfaty C. Exposing synonymous mutations. Trends Genet. 2014;30:308-21.

71. Kristofich J, Morgenthaler AB, Kinney WR, Ebmeier CC, Snyder DJ, Old WM, et al. Synonymous mutations make dramatic contributions to fitness when growth is limited by a weak-link enzyme. PLOS Genet. 2018;14:e1007615.

72. Walsh IM, Bowman MA, Santarriaga IFS, Rodriguez A, Clark PL. Synonymous codon substitutions perturb cotranslational protein folding in vivo and impair cell fitness. Proc Natl Acad Sci. 2020;117:3528-34.

73. Fuchs BB, Mylonakis E. Our paths might cross: the role of the fungal cell wall integrity pathway in stress response and cross talk with other stress response pathways. Eukaryot Cell. 2009;8:1616-25.

74. Sanz AB, García R, Rodríguez-Peña JM, Arroyo J. The CWI pathway: regulation of the transcriptional adaptive response to cell wall stress in yeast. J Fungi. 2018;4:1.

75. García R, Pulido V, Orellana-Muñoz S, Nombela C, de Vázquez Aldana CR, Rodríguez-Peña JM, et al. Signalling through the yeast MAPK cell wall integrity pathway controls P-body assembly upon cell wall stress. Sci Reports. 2019;9:1-13.

76. Lesage G, Shapiro J, Specht CA, Sdicu A-M, Ménard P, Hussein S, et al. An interactional network of genes involved in chitin synthesis in Saccharomyces cerevisiae. BMC Genet. 2005;6:8.
77. Matsushika A, Suzuki T, Goshima T, Hoshino T. Evaluation of Saccharomyces cerevisiae GAS1 with respect to its involvement in tolerance to low $\mathrm{pH}$ and salt stress. J Biosci Bioeng Elsevier. 2017;124:164-70.

78. Gietz RD, Woods RA. Transformation of yeast by lithium acetate/singlestranded carrier DNA/polyethylene glycol method. Methods Enzymol. 2002;350:87-96.

79. Engebrecht J, Brent R, Kaderbhai MA. Minipreps of plasmid DNA. Curr Protoc Mol Biol. 1991;15:1.

80. Lõoke M, Kristjuhan K, Kristjuhan A. Extraction of genomic DNA from yeasts for PCR-based applications. Bio Tech. 2018;50:325-8. https://doi. org/10.2144/000113672.

81. Matsui T, Ehrenreich IM, Mackay T, Stone E, Ayroles J, Baye T, et al. Geneenvironment interactions in stress response contribute additively to a genotype-environment interaction. In: Gibson G, editor. PLOS Genet. 2016;12:e1006158.

82. Pais TM, Foulquié-Moreno MR, Thevelein JM. QTL mapping by pooledsegregant whole-genome sequencing in yeast. Methods Mol Biol. 2014;1152:251-66.

83. Ausubel FM, Brent R, Kingston RE, Moore DD, Seidman JG, Smith AJ, et al. Current protocols in molecular biology. USA: Wiley; 1998.

84. Langmead B, Salzberg SL. Fast gapped-read alignment with Bowtie 2. Nat Methods. 2012;9:357-9

85. Li H, Handsaker B, Wysoker A, Fennell T, Ruan J, Homer N, et al. The Sequence Alignment/Map format and SAMtools. Bioinformatics. 2009;25:2078-9.

86. Picard Tools_By Broad Institute [Internet]. [cited 2021 Aug 15]. Available from: https://broadinstitute.github.io/picard/.

87. Magwene PM, Willis JH, Kelly JK. The statistics of bulk segregant analysis using next generation sequencing. In: Siepel A, editor. PLoS Comput 2011;7:e1002255

88. Mansfeld BN, Grumet R. QTLsegr: An R package for bulk segregant analysis with next-generation sequencing. Plant Genome. 2018;11:0.

\section{Publisher's Note}

Springer Nature remains neutral with regard to jurisdictional claims in published maps and institutional affiliations.

Ready to submit your research? Choose BMC and benefit from

- fast, convenient online submission

- thorough peer review by experienced researchers in your field

- rapid publication on acceptance

- support for research data, including large and complex data types

- gold Open Access which fosters wider collaboration and increased citations

- maximum visibility for your research: over $100 \mathrm{M}$ website views per year

At BMC, research is always in progress.

Learn more biomedcentral.com/submissions 